time. Following up with undecided patients is also critical.

What is most important is that we family physicians integrate ACP with our patients, exploring what works best in context of our own practices.

Marc Tunzi, MD, MA

Natividad Medical Center, Salinas, California and the Department of Family and Community Medicine, University of California, San Francisco, San Francisco, CA

William Ventres, MD, MA Department of Family and Preventive Medicine, University of Arkansas for Medical Sciences, Little Rock, AR

doi: 10.3122/jabfm.2019.04.190110

To see this article online, please go to: http://jabfm.org/content/ 32/4/000.full.

\section{Re: Better Doctor-Patient Relationships Are Associated with Men Choosing More Active Depression Treatment}

To the Editor: I commend David Kealy and colleagues ${ }^{1}$ on their work on the doctor-patient relationship and men's choice of depression treatment. However, I do have a few concerns that would benefit from clarification.

First, the gender of the physician is an important covariate that should be accounted for in any doctorpatient relationship, as it affects this dynamic and its outcomes. $^{2}$ Roter and colleagues ${ }^{3}$ showed that female physicians engaged the patient in more positive conversation, gave more information, and built more partnership compared with the male physician; similarly, when patients are with female physicians, patients engage in more positive discussion and partnership building compared with male physicians. ${ }^{3}$ This article highlights men's choice regarding treatment and the relationship with their physician; controlling for the physician's gender could help improve the understanding of this doctorpatient relationship.

Second, the questionnaire implied that primary care doctors would administer the hypothetical treatment preference. Although I agree that primary care doctors often manage treatment-resistant depression, ${ }^{4}$ there exists a substantial section of the population that are referred to psychiatrists by primary care doctors. ${ }^{5}$ This article does not account for this population, especially given that attitudinal differences exist in managing depression and in terms of "professional ease in dealing with patients with depression" between general practitioners and psychiatrists. ${ }^{6}$ Thus, although the findings may apply to the primary care population, it excludes the treatment of depression in men managed by psychiatrists.

Ayodeji Otufowora, MBBS, MPH, CPH

Department of Epidemiology, College of Public Health and Health Professions and College of Medicine, University of Florida, Gainesville, FL, USA
To see this article online, please go to: bttp://jabfm.org/content/ 32/4/000.full.

\section{References}

1. Kealy D, Rice SM, Ferlatte O, Ogrodniczuk JS, Oliffe JL. Better doctor-patient relationships are associated with men choosing more active depression treatment. J Am Board Fam Med 2019;32:13-9.

2. Bertakis KD. The influence of gender on the doctor-patient interaction. Patient Educ Couns 2009;76:356-60.

3. Roter D, Lipkin M Jr., Korsgaard A. Sex differences in patients' and physicians' communication during primary care medical visits. Med Care. 1991;29:1083-93.

4. Schwenk TL, Evans DL, Laden SK, Lewis L. Treatment outcome and physician-patient communication in primary care patients with chronic, recurrent depression. Am J Psychiatry 2004;161:1892-901.

5. Peterson BD, Pincus HA, Suarez A, Zarin DA. Datapoints: referrals to psychiatrists. Psychiatr Serv 1998;49:449-449.

6. Kerr M, Blizard R, Mann A. General practitioners and psychiatrists: comparison of attitudes to depression using the depression attitude questionnaire. Br J Gen Pract 1995; 45:89-92.

doi: 10.3122/jabfm.2019.04.190079

The above letter was referred to the author of the article in question, who offers the following reply.

\section{Response: Re: Better Doctor-Patient Relationships Are Associated with Men Choosing More Active Depression Treatment}

To the Editor: We thank Dr. Otufowora for commenting on our work regarding the doctor-patient relationship and men's choice of depression treatment ${ }^{1}$ and for raising concerns about the potential role of the physician's gender and the specialist status of the treatment provider.

Rather than address the abovementioned questions, our study focused on men's overall experience of the quality of their relationship with their family physician. Although female physicians may be perceived as more caring with regard to depression management, ${ }^{2}$ some research suggests complex interactions between patient and physician gender and whether the physician adopts a patient-centered orientation. ${ }^{3}$ Thus, although gender matters, the nature of the doctor-patient communication is also important. We suspect similar interactions regarding the treatment contextwhether primary care physician or mental health specialist-in that the quality of the relationship would remain influential. Indeed, research has shown considerable "provider effects" among psychiatrists, with some achieving superior outcomes prescribing placebo to others prescribing antidepressants. ${ }^{4}$

Considering the risks for suicide and atypical depression presentations among men, ${ }^{5}$ a better understanding of men's treatment engagement-including 